\title{
A história das Ideias como vocação transdisciplinar em José Sebastião da Silva Dias e José Esteves Pereira
}

\author{
The History of Ideas as a transdisciplinary vocation in José Sebastião da Silva Dias \\ and José Esteves Pereira
}

Resumo: A partir do prisma analítico da História da Historiografia este artigo começa com a defesa de uma conciliação entre História das Idéias, História dos Intelectuais e Intellectual History. Esta investigação principia com o esboço de um ensaio teórico. São abordadas, em dois capítulos, duas personalidades, José Sebastião da Silva Dias e José Esteves Pereira, que tentaram uma História das Ideias diferente da tradicional, o primeiro de meados de Novecentos até aos anos 90, criando escola, e o segundo até aos dias de hoje. Sublinha-se a tese segundo a qual estes estudiosos refletiram teoricamente sobre a História das Ideias, salvaguardando uma perspectiva interdisciplinar e transdisciplinar resultando fundamental analisar algumas recensões que Silva Dias publicou nos primeiros dois anos da Revista Cultura História e Filosofia (1982-1983) e textos teóricos do seu discípulo.

Palavras-chave: José Silva Dias; José Esteves Pereira História das Ideias; História dos Intelectuais e História Intelectual.

\section{Nuno Bessa Moreira}

Doutor em História

Faculdade de Letras da Universidade do Porto, Investigador do CITCEM

knunoclio@gmail.com

\begin{abstract}
From the analytical perspective of the History of Historiography this article begins with the defense of a conciliation between History of Ideas, History of Intellectuals and Intellectual History. It begins with the outline of a theoretical essay. Two personalities, José Sebastião da Silva Dias and José Esteves Pereira, were approached in two chapters, who show a history of ideas different from the traditional one, the first from the mid-nineties until the 90 s, creating a school, and the second until nowadays. The thesis that these scholars theoretically reflected on the history of the ideas, safeguarding an interdisciplinary and transdisciplinary perspective, is essential to analyze some of the reviews that Silva Dias published in the first two years of the Revista Cultura História e Filosofia (1982-1983) and theoretical texts of his disciple.
\end{abstract}

Keywords: José Silva Dias; José Esteves Pereira History of Ideas; History of Intellectuals and Intellectual History. 


\section{Ponto Prévio: A História da Historiografia como História Intelectual (Prisma de análise e inquietante objeto numa encruzilhada)}

Neste estudo, torna-se imperativo revisitar ensaística e brevemente a história intelectual que propomos como agregadora de diversas possibilidades, na encruzilhada da história das ideias, da história dos intelectuais e da intellectual history, sem esquecer a sociologia histórica e a história das ciências humanas, de forma a conciliar os âmbitos referidos, sinalizando e enfatizando a pluralidade de que se reveste a história intelectual, que pode ser encarada como positiva, negativa, enquanto oportunidade ou foco de apreensão, sendo passível de suscitar reações intermédias, nas quais as polarizações comparecem matizadas. A nossa abordagem será histórico-historiográfica, centrando-nos na evolução teórico-metodológica e epistemológica da História Intelectual na confluência dos domínios referidos, sobretudo do primeiro. A História Intelectual da Historiografia que defendemos possui, no entender de Horst Walter Blanke, referido por João Ohara, duas vertentes: a afirmativa e a crítica. Partiremos da primeira, tentando evitar celebrações ou comemoracionismos, para a segunda. Ohara afirma o seguinte:

A história de uma disciplina seria, portanto, a crônica de como grandes indivíduos (geralmente homens, brancos e europeus) teriam vencido a superstição e o irracionalismo para estabelecerem os fundamentos de nosso campo disciplinar. [...] Tendo em mente apenas a produção em língua alemã, Horst Walter Blanke (2005: 227-232) propôs uma tipologia da História da Historiografia dividida em dez tipos que se organizariam em torno de duas funções principais: de um lado, a função afirmativa, cujo objetivo é afirmar o primado de determinadas posições ideológicas, ou determinadas maneiras de pensar a história; de outro, a função crítica, destinada a desestabilizar as narrativas afirmativas, mostrando os limites e os problemas de certas maneiras de pensar a história. [...] Assumindo que essa tensão entre afirmação e crítica não é dialética, ou seja, não é capaz de produzir um resultado sintético, o historiador da historiografia faz bem em declarar suas cores. Não se trata de declarar a superioridade de um dos polos sobre o outro, mas de estabelecer a direção do trabalho a ser realizado. Isso porque ambos os esforços são legítimos e importantes para o campo, e a ausência de um deles produz situações problemáticas: o dogmatismo da afirmação sem crítica ou a paralisia 
da incapacidade de estabelecer noções positivas de trabalho (OHARA, 2017: 9-10).

Pode objetar-se que intelectual (como adjetivo) é toda a História, dado que consubstancia as ações humanas num dado tempo e espaço, aplicando-se o mesmo raciocínio à Historiografia (consignada à pesquisa, investigação e escrita dos cultores de Clio, profissionais ou não). A História Intelectual da Historiografia que defendemos cruza a História das Idéias, na sua vertente menos abstrata e sociocultural, com a História dos Intelectuais de matriz francesa e com uma Intellectual History interdisciplinar que não enjeite a análise de discurso, alargando bastantes horizontes. Concordamos com a necessidade de conciliar História das Ideias, História das Ciências Humanas e sociologia do Conhecimento, proposta recentemente por Frederico Ágoas (2015: 465-482). Esta é uma primeira tentativa nossa sugerir uma história Intelectual da Historiografia e será aprofundada em ocasiões futuras.

No que respeita à História das Ideias, interessa ter presente o trabalho realizado por Arthur Lovejoy, de cariz eventualmente essencialista, desde os anos 30, ou Preston King, que alargou o seu objeto de análise, defendendo, na década de 80, a interdisciplinaridade, até Mark Bevir nos nossos dias.

No que concerne à História dos Intelectuais, as suas origens são oitocentistas, a forma como as várias gerações dos Annales a trataram é equacionada sem esquecer a proliferação de direções tomadas a partir dos anos 80 . Na atualidade, tem cabimento uma referência a Diogo Ramada Curto, que cruza preferencialmente a Sociologia Histórica com a História Cultural e dos Discursos ou Luís Trindade, que promove a História Cultural do Político.

A Intellectual History, de inspiração anglo-saxónica, não pode ser vista em bloco. Na primeira metade do século XX estudava as ideias dos intelectuais tendo em conta os seus percursos sociais e continuou a fazê-lo até hoje, mesmo quando nos anos 70 surgiu o Linguistic Turn (no caso da historiografia mais voltado para a literatura e a crítica literária do que para uma vertente estritamente linguística resultando discutível, plural e até equívoco), vigente desde a década referida, com personalidades como Hayden White ou Dominick LaCapra (bem distintas entre si). Em 1980, em Cornell, vários historiadores discutiram maioritariamente sob o prisma referido: a Modern Intellectual History, com a presença significativa do historiador francês Roger Chartier, que não pertencia ao Linguistic Turn e defendia a conciliação entre a cultura erudita e popular, 
entre a produção e o consumo. A sua inclusão pode ter acontecido para lançar pontes e abrir o espetro do Linguistic Turn, colocando-o em diálogo com perspectivas diferentes. Todavia, o Linguistic Turn estava na moda e foi analisado por John Toews, que cita William Bowsma, e refere a importância nos anos 80 de uma Intellectual History voltada para significados e sentidos da linguagem (TOEWS, 1987). Esta perspetiva foi criticada por Russel Jacoby, em 1992, defensor de uma história intelectual de cariz mais social (JACOBY, 1992). Estas tensões no interior da Intellectual History provam a relevância da discussão e do debate, demonstrando que o Linguistic Turn nunca foi totalmente hegemônico, mesmo na década em que surgiu, coexistindo com outras tendências.

$\mathrm{Na}$ atualidade, a procura de sincretismos e pontos de contato tem vindo a ganhar terreno. De tal forma, que a busca de espaços geográficos mais alargados consagrou $a$ Golbal Intellectual History, que tem vindo a ser teoricamente discutida e comparada com a World History ou a Universal History, mormente na obra homónima publicada em 2013, uma coletânea, dirigida por Samuel Moyn e Andrew Sartry (MOYN \& SARTORI, 2013). Para além do comparatismo, a interdisciplinaridade tem vindo a ser afirmada e defendida, mormente na releitura de Modern Intellectual History, coordenada pelo mesmo Sartori e por Darrin Mac Mahon e dada à estampa em 2015, com o título Rethinking Modern Intellectual History (MOYN \& MAC MAHON, 2014). Em 2015, em contexto britânico, surgiu o Companion to Intellectual History, onde é patente a crítica de um ponto de vista estritamente assente em aspetos linguísticos e literários (aliás o Linguistic Turn não teve, de forma alguma, o mesmo acolhimento em solo britânico que tivera nas décadas de 70 e 80 nos Estados Unidos) (WHATMORE \& YOUNG, 2015). Destacaremos, em seguida, as relações da História Intelectual (em sentido lato) com a História das Ideias, por ser esta a temática central deste estudo (reservando as ligações com a História dos Intelectuais e a Intellectual History para próximos trabalhos).

\section{História Intelectual e História das Idéias. Relações complexas, paradoxos, em busca de conciliações}

A História da Historiografia que praticaremos neste artigo aproxima-se de uma certa forma de concretizar a História das Ideias, que não deve ser encarada como um bloco monolítico, estanque, impermeável a algumas influências. Para melhor especificar esta afirmação, convém enquadrá-la diacronicamente, traçando a génese da História das 
Ideias, encarada incialmente sob a égide de um prisma fenomenológico, surgida devido ao impulso das Ciências do espírito no século XIX alemão. Por seu turno, a perspectiva ontológica da História das Ideias institucionalizou-se devido ao impulso e à ação de Artur Lovejoy, que em 1936 publicou um livro, The Great Chain of Being, lançando uma revista quatro anos volvidos, intitulada The Journal of History of Ideas (MESQUITA, 2011: 7$8)$. $^{1}$

Também nos eximimos a partilhar inteiramente a concepção ontológica impulsionada por Lovejoy, que pode ser descrita do modo escolhido por Gustavo Mesquita: “A inflexão da ênfase fenomenológica para a ênfase ontológica na abordagem dos temas e problemas de História das ideias ocorreu somente a partir de 1936, quando Artur Lovejoy publica The Great Chain of Being, obra que é considerada pelos contemporâneos como crucial para a redefinição de seus paradigmas e fundamentos teóricos $(\ldots)^{\prime 2}$.

Alguma historiografia considera que Lovejoy colocara a tónica no carácter abstrato de certas ideias. O enfoque do estudioso citado é essencialmente filosóficoconceptual, centrando-se na ideias-unidade e pode ser encarado como metafísico. Tornase relevante apontar o ponto de vista de Carl Knight, que dá conta de um interessante debate em torno da recepção das ideias-unidade. O investigador britânico filia-se num entendimento deste tipo de ideias como elementos e até átomos, contrapondo a sua leitura àquela que consigna as ditas instâncias como compostos e complexos (catalisadores de uma semelhança familiar) citando uma passagem de The Great Chain of Being, na qual o seu autor assume um exemplo retirado das ciências naturais, mormente da química, não deixando de ser curioso, dado que muitos imputam a Lovejoy uma interpretação progressiva e maioritariamente metafísica das ideias-unidade.

Na nossa perspectiva, The Great Chain of Being admite e alberga as duas leituras principais esboçadas às ideias-unidade. No início, Lovejoy envereda pela decomposição de sistemas em compostos, elementos e átomos, mas ao longo da obra explora e permite outros caminhos, permeáveis a interpretações metafísicas, próprias e alheias. Todavia, a questão não é assim tão simples e linear e o próprio Carl Knight o reconhece quando problematiza o conceito de ideia-unidade, baseando-se nas três principais unit-ideas apontadas por Lovejoy: os princípios de plenitude, continuidade e gradação, postulando

\footnotetext{
${ }^{1}$ MESQUITA, 2011: 7-8.

2 Ibidem: 8.
} 
a eventual permanência do primeiro princípio enunciado, aplicável a diferentes áreas de saber desde Platão até Kant (KNIGHT, 2012: 197-198).

A discussão acerca da recepção das unit-ideas de Lovejoy é relevante porque demonstra a necessidade de evitar generalizações abusadoras, e a densidade do assunto em questão, gerador de instigante controvérsia. Contudo, importa ampliar o espetro de análise e abordar, eventualmente, outras obras de Lovejoy, ou o Journal of History of Ideas, que fundou. Todavia, por razões que se prendem com a vastidão deste percurso e por economia narrativa, aliada à vontade de fazer sobressair um conjunto mais vasto, referimos, em seguida, brevemente, o Journal. No entender de Anthony Grafton em meados do século XX a História das Ideias: “(...) rose like a new sign of the zodiac over large áreas of American culture and civilization (...). The Journal, in the twenty years of its Foundation, attracted attention from many quarters, some of them unexpected (...)" (GRAFTON, 2006: 1-2).

O Journal of History of Ideas situava-se entre estudos mais científicos e ensaios, cobrindo uma vasta área entre a história e a filologia, por um lado, e as artes liberais, por outro, mais próximas dos conhecimentos úteis, configurando, no entender de Grafton, uma zona sísmica e um novo campo, fruto de um ecletismo claro, em nosso entender, razão principal de uma grande preponderância do periódico nas primeiras décadas da sua existência, mormente no pós Guerra e nos anos 50: "The main reason for the Journal's proeminence was that it represented a new field, apeallingly located between disicplines as the Journal was between other sorts of periodical (...)" (2006: 2). Assim, depois deste enquadramento teórico-conceitual, convém postular que nos afastamos de uma História estritamente conceptual ou abstrata das Ideias, dado que as últimas não devem ser separadas das intenções dos seus autores.

\section{Achegas sobre a importância de Silva Dias para uma Nova História das Ideias}

\subsection{Enquadramento biobibliográfico}

José Sebastião da Silva Dias nasceu em Arcos de Valdevez a 9 de Fevereiro de 1916 e faleceu em Lisboa a 23 de Novembro de 1994. Luís Reis Torgal, que foi seu aluno e discípulo, dedicou-lhe um artigo recente intitulado "Acerca de Silva Dias no seu 
centenário. Evocação em jeito de História e de memória", estudo que dialoga com outros trabalhos/depoimentos sobre a mesma personalidade publicados pelo Professor Catedrático aposentado da Faculdade de Letras da Universidade de Coimbra, mormente na Revista Biblos, em 1994, aquando do falecimento de Silva Dias (In Memoriam), texto também dado à estampa, no mesmo ano, na Revista de História das Ideias, de cariz mais pessoal, ou a entrada para o Dicionário de Historiadores Portugueses. Reis Torgal refere os dois números coletivos dedicados ao seu mestre pela Revista de História das Ideias, ainda em vida deste, em 1986-1987, por ocasião da sua jubilação. A Revista Cultura História e Filosofia também lhe rendeu homenagem semelhante, no último ano referido. Aliás, a atitude prodigalizada pelos dois periódicos não é de estranhar, dado que Silva Dias esteve ligado à fundação de ambos. Na primeira revista citada encontra-se também um notável esforço para uma bibliografia de Silva Dias, organizada por Maria do Rosário Azenha, publicada também autonomamente pela Faculdade de Letras de Coimbra. Todos estes trabalhos de e sobre Silva Dias são referenciados por Luís Reis Torgal no seu estudo de 2016, que iremos seguir de modo mais circunstanciado, destacando alguns elementos e momentos do percurso intelectual e biobibliográfico da personalidade escolhida (TORGAL, 2016: 57-85).

Luís Reis Torgal considera que nos anos 40/50 Silva Dias foi mais um ideólogo do que um filósofo, pelo menos se entendermos esta designação como própria de quem criou um sistema filosófico, algo que não terá acontecido com o historiador em causa. Silva Dias era, nos anos referidos, um católico "integralista moderno", sem se ligar ao Estado Novo, mas próximo do círculo deste: “Com certeza que abordou temas vários, de ordem religiosa, política, social e cultural, com profundidade, mas o que vem ao de cimo é, sem dúvida, a sua ideologia católica de tipo (por assim dizer) (...)” (TORGAL, 2016: 62). Silva Dias presidiu ao CADC (Centro Académico da Democracia Cristã) em 19391940 e em 1940-1941 (ano da sua licenciatura em Direito) e publicava artigos na respetiva revista, a Estudos, desde finais dos anos 30.

A 4 de setembro de 1941, Silva Dias deu à estampa, no periódico Acção Semanário da Vida Portuguesa, um artigo, intitulado Toque de Clarim, que pode representar, eventualmente, uma evolução na continuidade, mas sem mudanças de fundo, no entender de Luís Reis Torgal, constituindo esse texto um momento possivelmente seminal para a criação do grupo Amigos de Braga.

Em 1947, Silva Dias defendeu a Democracia Cristã nos seus Estudos Políticos e três anos volvidos reafirmou uma evolução na continuidade, apoiando-se em Maritain 
para colocar em prática um catolicismo cada vez mais distante do integralismo, pelo menos da sua fação mais ligada ao clericalismo, mas não defendia propriamente o progressismo. Fora da Igreja, opunha-se ao capitalismo e ao comunismo, aceitando cargos do Estado.

Para Silva Dias, a erudição é necessária, mas não pode constituir um fim em si mesma, para o qual tendam a convergir interesses e vontades centrados numa metodologia exclusivista. Assim, o estudioso critica dois historiógrafos integralistas, João Ameal e Alfredo Pimenta, que deram à estampa, respetivamente Rumo da Juventude (1935) e Novos Estudos Filosóficos e Críticos (1942) e faz reparos incisivos a ambos. O Historiador começou a afirmar-se na década seguinte, sempre atento aos problemas sociais, preferindo, para ir ao seu encontro, a expressão mais lata de historiografia, em detrimento da historiografia, mais redutora na visão de Silva Dias. Em 1957-1958 tornouse docente da Faculdade de Letras de Coimbra e leitor, na década seguinte, de obras da escola de Frankfurt e de Gramsci e Lukacs, continuando a atacar, de modo claro, o marxismo ortodoxo, aproximando-se criticamente dos Annlaes e da Nouvelle Histoire, conforme resulta evidente no depoimento de Luís Reis Torgal.

Todavia, do ponto de vista historiográfico, as correntes culturais constituíram sempre uma temática de eleição de Silva Dias, subalternizando, no entender de Reis Torgal, a razão política: "A História de Silva Dias assentava, com efeito, fundamentalmente, no estudo das correntes culturais, e nomeadamente das correntes culturais de espiritualidade, fossem elas quais fossem (...)" (2016: 72). Todavia, pode aventar-se a hipótese segundo a qual a espiritualidade comparecia nos interstícios do assunto apontado, acentuando-lhe uma componente problemática e problematizante, discreta, mas robusta e atuante.

Centrando-nos agora na investigação historiográfica realizada por Silva Dias, importa sublinhar que nesta o ideólogo católico cede em larga medida o seu lugar ao historiador, atento desde sempre a problemáticas da Época Moderna e, progressivamente, sobretudo a partir de 1970, mormente após 1974, a assuntos relativos à contemporaneidade, embora estes sejam comparativamente bastante menos frequentes. Contudo, em ambos os casos, nota-se nestas escolhas um empenho na modernização do conhecimento, como bem nota Luís Reis Torgal, sublinhando que quando Silva Dias entrou como docente na Faculdade de Letras da Universidade de Coimbra, no já referido ano de 1957-1958, começou a lecionar a disciplina de História da Cultura, uma novidade imposta pela reforma das Faculdades de Letras, ocorrida precisamente nesse ano, tendo 
sido incumbido, pelo Conselho Escolar, do ensino de História da Filosofia em Portugal, em substituição de Joaquim de Carvalho, que faleceu a 27 de Outubro de 1958. Precisamente nesse ano, o historiador tornou-se docente de História da Cultura Moderna, continuando a contemporânea a não existir, estando ausente dos diplomas legais da reforma aludida (Torgal, 2016: 73).

A partir de 1964-1965, com base numa experiência no mesmo sentido realizada no ano anterior, Silva Dias introduziu na Faculdade de Letras de Coimbra os Seminários do fim da Licenciatura, dos quais Luís Reis Toral foi aluno (TORGAL, 2016, p. 74), versando este uma área que até então não havia sido aprofundada, o tradicionalismo contrarrevolucionário, o mesmo acontecendo com o Liberalismo, trabalhado por outros alunos. Silva Dias não era muito próximo de Veiga Simão, nem apreciava, segundo consta, Marcello Caetano. Todavia, no entender deLuís Reis Torgal, as reformas educativas do primeiro, algumas políticas do segundo, bem como a ação do Instituto de Alta Cultura no domínio da investigação e o trabalho de José Gouveia Monteiro enquanto reitor (1970-1971), criaram condições institucionais para a publicação de algumas dessas teses de licenciatura (TORGAL, 2016: 75).

No ano de 1971 e em 1973 no Expresso e no República, mas também depois do 25 de Abril de 1974, José Sebastião da Silva Dias manifestou ideias inovadoras no que tange à necessidade de reformas da Universidade, defendendo, no primeiro artigo citado, idéias similares às dos membros da Ala Liberal da Assembleia Nacional, os Professores Doutores Miller Guerra e Pinto Machado, pugnando pela articulação entre a referida instituição, os restantes níveis de ensino e a Sociedade no seu conjunto.

No que tange à censura, Luís Reis Torgal refere que a obra de Silva Dias Escândalo de verdade foi alvo de exame apertado pelo militar Ávila Madruga, que apontou o Catolicismo Social do autor, afirmando a inspiração colhida na Rerum Novarum, de Leão XIII e nas Encíclicas de Pio XI e reconhecendo que essas influências poderiam ser mal interpretadas. Mas, ainda assim, autorizou a publicação.

Recorde-se que Silva Dias, além de ter integrado o Conselho Diretivo da Faculdade de Letras de Coimbra, em 1974, e a Comissão Instaladora da Faculdade de Ciências Sociais e Humanas da Universidade Nova de Lisboa, criou, na Faculdade de Letras da Universidade de Coimbra, o Instituto de História e Teoria das Ideias (1974) e dirigiu, primeiro, o Projeto de História das Ideias em Portugal nos Séculos XVIII e XIX e, posteriormente, o Centro de História da Sociedade e da Cultura da Universidade de Coimbra (1976-1979) (MENDES, 1996: 305). 
Amado Mendes apresenta brevemente três exemplos relativos à reflexão de Silva Dias sobre a sua prática historiográfica, respetivamente sobre os Descobrimentos e a Problemática Cultural do século XVI (1973); O pombalismo e o projeto político (1984) e os Primórdios da Maçonaria em Portugal (1980, em colaboração com Graça Silva Dias) (1996: 305-311).

Em qualquer dos casos, do nosso ponto de vista, Silva Diasdesenvolve, de modos diferentes, uma história cultural das idéias, evitando uma estrita historiografia tradicional a esse nível assente no puro apuramento de fatos, que não enjeita, mas procura partir desse substrato para a irradiação de uma via mais explicativo-interpretativa, alicerçada numa compreensão de idéias, dos contextos e da Sociedade. $\mathrm{O}$ autor não dispensa a pesquisa documental nem a fatual. São fundamentais, mas insuficientes, concitando perspetivas e interpretações que neles se alicercem, tanto no plano da crónica como no da descrição, mas que visem uma compreensão mais alagada, se possível sistemática e, idealmente, sistémica. Silva Dias refere o termo estrutura e afirma procurar as suas conexões, significado e sentido. No entanto, em nosso entender, recusa o estruturalismo, que é algo bem diferente, pelo que pode acarretar, no limite, de implicação exclusiva nos discursos e na sua dinâmica interna, esquecendo contextos, relações, esquecimento esse que Silva Dias não praticou, bem pelo contrário.

\subsection{Defesa de uma História das Ideias Pluridisciplinar no arranque da Revista Cultura (1982-1983)}

Seguindo a pista e a sugestão de Amado Mendes (que também a concretizou parcialmente e de modo esparso mas bem fundamentado), procuramos de imediato analisar as reflexões teórico metodológicas sobre historiografia e história das ideias patentes nas recensões críticas publicadas por Silva Dias nos dois primeiros anos da Revista Cultura História e Filosofia, tendo em conta o impulso constituído pelas seguintes palavras e pelo trabalho que consubstanciaram, pormenorizando e alargando o respetivo espectro empírico: “(...) na última década (...) como historiador (dos inícios dos nos 80 aos inícios dos anos 90), encontramos elementos de grande interesse na sua numerosa colaboração na revista Cultura-História e Filosofia (...) não só em artigos como nas próprias recensões a diversas obras (...)" (MENDES, 1996: 309).

No que se refere às recensões publicadas na Revista Cultura... por Silva Dias, começaremos sempre por selecioná-las e agrupá-las de um modo que permita destacar 
primeiro as que se reportam tematicamente a assuntos de história dos ideais ou da filosofia e, em seguida, analisando em seguida as que se dedicam a temas mais empíricos da história da cultura. Assim, logo no número inaugural, em 1982, Silva Dias sublinha, inicialmente, três estudos recenseados, respetivamente da autoria de Georges Gusdorf, François Chatelêt e Jean Dagan.

Percebe-se que Silva Dias apreciou a densidade do trabalho de Gusdorf e, em contrapartida, parece menos confortável com o esforço de François Chatelêt enquanto diretor da Histoire des Ideologies, cujo terceiro volume analisa, considerando-a uma obra interessante e útil no plano da divulgação, ao qual se destina, mas criticando as omissões bibliográficas existentes:

(...) trata-se, no entanto, de um conjunto de textos para um público médio, elaborado por quem conhece em profundidade os problemas. Cada rubrica termina por uma bibliografia de seis a oito espécies, cujas omissões fundamentais são frequentes e clamorosas, e que em geral não constitui sequer um guia para um leitor interessado no aprofundamento das matérias. No final do volume insere-se um útil quadro sinótico (...) (DIAS, 1982b: 553).

Resulta assim claro que, na forma como conceptualiza a História das Ideias, Silva Dias valoriza o aprofundamento das matérias em análise, não lhe bastando bons instrumentos heurísticos ou trabalhos de divulgação, dado que defende a abordagem da sua complexidade, algo que, em sem entender, terá faltado no volume dirigido por Chatelêt, apontando outra falta à secção da autoria do historiador da filosofia francês: “Lástima que a secção Le Travail Et L'Industrie, da responsabilidade do próprio François Chatêet se circunscreve quase ao marxismo, passando em claro a escola clássica inglesa e a escola liberal francesa, ideologicamente tão importantes e ricas" (DIAS, 1982b: 554).

Resta saber se a ideologia de Chatelêt terá pesado na análise, apesar da robustez do reparo de Silva Dias, bem estribado epistemológica e retoricamente na necessidade de ver a realidade através de diversos prismas. Se provas faltassem da aspiração de Silva Dias, pelo menos a nível teórico, a uma história das idéias de teor rigoroso e sistemático, as suas palavras sobre L'Histoire de l'esprit humain dans la pensée française, de Jean Dagen, contribuiriam de modo claro para o cumprimento de tal desiderato, ainda que não resista, no dealbar da sua recensão, a uma especificação de teor metodológico, reconhecendo que a obra em causa constitui uma história da história do espírito humano 
e não uma história tout court. O título não deve induzir em erro. Não se trata de uma história do espírito humano, mas de uma história da história do espírito humano. O tema tem sido aflorado por diversos autores. É, contudo, a primeira vez que sofre um estudo sistemático e rigoroso: “(...) O espírito é a capacidade de formar ideias e a aptidão para decidir da sua justeza" (DIAS, 1982c: 551).

Percebe-se que Silva Dias concorda com esta definição de espírito, ligando-o à formação de ideias. Contudo, para Dagen, como para Silva Dias, ambas as instâncias possuem uma história ao longo do tempo, não postergando nem obliterando as características internas da ideia-força em questão (DIAS, 1982c: 552). Sem referir os conceitos explicitamente, estão presentes a diacronia e a sincronia, defendidas por Silva Dias. Existem ressonâncias nesta recensão da leitura efetuada sobre Gusdorf. Todavia, no texto sobre Dagen, o entusiasmo parece-nos ainda maior e o comentador não deixa de observar algo diferente neste caso; a presença de uma parte sobre a passagem da ideia a mito, apontando Silva Dias a historicidade e diversidade dessa passagem e do simbólico que ela configura e incorpora.

Ainda no primeiro número da Revista Cultura ..., em 1982, Silva Dias debruçase sobre temáticas aparentemente menos teórico-metodológicas do ponto de vista temático, mas não se exime a sobre elas impender reflexões desse teor. Assim, não deixa de ser curioso que quando se debruça sobre a publicação do Cancioneiro da Biblioteca Nacional não esconde o seu regozijo acerca da natureza documental deste volume e da importância da conservação de fontes, ainda que reconheça que esta só se completa se a Biblioteca tiver funções mais amplas (DIAS, 1982a: 557).

No mesmo sentido da importância e da insuficiência da erudição, interessatranscrever a observação de Silva Dias sobre Portugal e a Universidade de Salamanca e a participação dos escolares lusos no governo do estudo, 1503-1512, de Armando de Jesus Marques: “(...) Não há saber histórico verdadeiro onde a erudição e a pesquisa de arquivo se acham de menos, muito embora, a essência de tal saber se encontre, quanto a mim para lá dessa instância. Digo-o com o à vontade de quem tem passado largas décadas da sua vida amarrado às páginas amigas de velhos manuscritos e de velhos livros (...)" (DIAS, 1982:g 554).

Quanto à edição em português de Viagem em Portugal, 1798-1802, Silva Dias elogia o trabalho do tradutor, António Feijó, e do prefaciador, Castelo Branco Chaves e é impossível não ver refletidas no seu comentário sobre o conteúdo do trabalho do viajante sueco influências que o historiador português recebeu dos Annales, mormente, 
neste caso, da História das Mentalidades, sob cujo prisma aborda o texto de Ruders: "A verdadeira importância desta obra deriva das profusas indicações sobre os costumes, a mentalidade, a vida doméstica as atividades quotidianas, o carácter, até certo ponto a instrução e a religião, dos habitantes da hoje chamada Grande Lisboa" (DIAS, 1982h: $555)$.

Em qualquer dos casos, Silva Dias sublinha a relevância de pesquisas metódicas e de uma exegese documental na análise a A Congregação do Oratório no Brasil de Ebion Lima: “(...) o Prof Ebion Lima pôs ao alcance dos estudiosos um estudo sério, isento e de fácil leitura, que reputo da maior utilidade (...)" (DIAS, 1982: 549). Na recensão a Quintana y el nacimiento del liberalismo em Espanha, de Albert Dérozier Silva Dias volta a destacar virtudes historiográficas anteriormente referidas, sublinhando o rigor dos métodos e a isenção do autor. Todavia, considera que este se deteve escassamente sobre a biografia de quintana, facto que Silva Dias lamenta, dado que um maior aprofundamento seria benéfico a uma historiografia portuguesa ainda não muito abundante sobre esta matéria (DIAS, 1982d: 552-553).

As recensões da autoria de Silva Dias no ano de 1983 começam pela leitura de duas obras do Professor José Luis Abellán da Universidade Complutense de Madrid. O Historiador das idéias português debruça-se, em primeiro lugar, sobre a reedição de $E l$ Erasmismo espanhol, classificado pelo leitor como ensaio, com os que considera serem os aspetos positivos e negativos do género, faltando-lhe, alegadamente, contrastaro Erasmismo com outras correntes culturais e de espiritualidade. Esse exercício comparativo fora realizado desde pelo menos os anos 60 por Silva Dias para o caso português. Com base nessa experiência e no exercício que consubstancia, Silva Dias foi tomando cada vez maior consciência de que alguns autores espanhóis se atinham, em seu entender erradamente, ao erasmismo, independentemente dos muitos méritos que alcançaram, colocando e inscrevendo Abellánna linha de autores como Marcel Battaillon, Eugénio Ascensio, Américo de Castro, Dâmaso Alonso. Mais uma vez, Silva Dias revela grande atualização bibliográfica. (DIAS, 1983a: 529).

Também merecemreservas, segundo o historiador das idéias português, os exageros nos quais Abellán (e outros) incorreram ao destacar a alegada irmandade entre o Erasmismo e os Cristãos Novos. A outra obra de Abellán sobre a qual Silva Dias escreve uma recensão no ano de 1983 é a História Crítica do pensamento espanhol. No primeiro volume, o seu autor desenvolve uma reflexão teórico-metodológica tendente a uma crescente afirmação de uma história da filosofia liberta de um regime autotélico e cada 
vez mais alargada, inscrita nas ciências compreensivo-comunicativas e, pela sua novidade, assume um carácter inspirador, partilhado por Silva Dias que concorda com a importância conferida por Abellánàs circunstâncias literárias, poéticas, socioculturais (e, entre estas, religiosas e políticas). No entanto, o recenseador não idealiza nem liberta de escolhos esta ligação da filosofia às ciências sociais preconizada porAbellán, e que desafiaobscurantismos: “(...) Crispa o cabelo cultural de boa parte desse magistério tudo o que saia do território de um obscurantismo denso (...). O horizonte (...) de Abellán tornou-se dependente de uma nova ótica mental (...)" (DIAS, 1983b: 536; 539).

Tal comoAbellán, Silva Dias pugna por uma história das idéias que incorpore interesses e vontades e não seja puramente abstrata, nem se enfeude numa disciplinaridade cuja história esboça, em busca de uma transdisciplinaridade remuneradora, característica da história das ideias e denuncia, sem meiguice, espartilhos disciplinares segregadores de preconceitos insanáveis e dicotomias indesejadas ou indesejáveis: “(...) Salientarei, sim, a ignávia e/ ou o cabotinismo, tresandando em saberes de outras eras, em que se atolam quantos, por esse mundo fora, temem a história das ideias (...)" (DIAS, 1983b: 541;543).

\section{Apontamentos sobre as reflexões teórico-metodológicas de José Esteves Pereira acerca da História da Ideias sob o signo da interdisciplinaridade}

No que tange à História das Idéias, José Esteves Pereira se tem preocupado em refletir teórico-epistemologicamente sobre este campo, reagindo, em nosso entender, como o seu mestre Silva Dias contra um certo economicismo e imperialismo da História Económica (MENDES, 1996: 310). Acompanharemos as suas indagações tendo por base a resposta ao inquérito sobre o oficio de historiador, publicada na Revista Ler História em 1989, mas também os dois primeiros estudos da compilação intitulada Sobre a História das Ideias Intervenções. Recensões (1982-1989), dada à estampa em 1992, salvaguardando a sua atualização recente em Percursos da História das Idéias (2004) e ainda o testemunho efetuado aquando da última lição, dada à estampa em 2015.

O inquérito corporiza, do nosso ponto de vista, uma afirmação clara da importância de Silva Dias no percurso do autor, à qual já aludimos anteriormente. José Esteves Pereira nasceu em Viana do Castelo em 17 de Setembro de 1944. Licenciou-se 
em Filosofia em Coimbra, no ano de 1970 tendo lecionado nessa cidade e sobretudo em Lisboa a convite do mestre (PEREIRA,2015: 101). No depoimento em consideração, Esteves Pereira sublinha que o interesse pela História se foi construindo e consolidando ao longo do tempo e utiliza uma imagem sugestiva, destacando depois a importância de Silva Dias, sem esquecer a referência (bem mais sumária) a Miranda Barbosa: “A História não apareceu no meu caminho de Damasco. Não sei quando o problema da temporalidade se me apresentou como questão fundamental, mas o certo é que o apelo da História veio a inscrever-se entre solicitações de compreensão de mim próprio, dos outros e do mundo (...)" (PEREIRA, 1989, p. 162).

O autor salvaguarda três dimensões fundamentais no seu trabalho historiográfico: a reflexão lógico-epistemológica da individualidade, da transfinitude e da diferença contribuíram, certamente, para que não enveredasse por modelos muito estruturantes de fazer história das ideias. Silva Dias insistiu, do ponto de vista teórico, mais numa idéia de sistema do que Esteves Pereira. Ambos eram, em nosso entender, avessos ao estruturalismo e aos exageros da história serial praticada pela segunda geração doa Annales, e da Cliomentria, com representantes na História Social Portuguesa sobretudo nas décadas de 70 e 80 . Por outro lado, Esteves Pereira, como aliás o seu mestre, não enveredou pelo marxismo, seguindo também uma matriz católica, presente na ideia de transfinitude. O alargamento das fronteiras disciplinares da História das Idéias, em direção à pluri, à inter e à transdisciplinaridade era desígnio comum entre as duas personalidades, desenvolvendo uma história cultural ampla das ideias onde cabiam a história política, a história económica (sem o economicismo), a da espiritualidade, a da literatura. Todavia, Esteves Pereira acentuou tematicamente sobretudo as duas primeiras.

Estes vários pressupostos ajudam a compreender muitas das intervenções escritaspelo historiador das ideias entre 1982 e 1988 (a análise das recensões ocorrerá em ocasiões futuras). A primeira, intitulada Sobre a História das Ideias foi inicialmente publicada no Jornal de Letras a 18 de Julho de 1983. Nela se nota que Esteves Perira rejeita uma História das Ideias epifenoménica face à História económica e social, recusando, em nosso entender, sem referir os termos explicitamente, o determinismo e o mecanicismo que possam estar implicados nesse modo de entendimento próprio de uma causalidade (esta expressão é utilizada e pelo autor) característica de uma vulgata marxista subjacenteaos novos programas de História aplicados em Coimbra a partir de 1974. Esteves Pereira também exprime reticências face à História das Doutrinas que passou a vigorar desde 1978, preferindo a correlação das ideias com o factum, proposta 
entre as duas datas citadas, evitando, todavia, o fatualismo: "Pode parecer, para alguns, que a história das ideias não passa do nível epifenómeno da história das concreções materiais ou do estudo dos produtos culturais que sejam o mero reflexo teórico da praxis (...)" (PEREIRA, 1992a: 17-18).

Esteves Pereira debruça-se, igualmente, sobre as relações da história das Idéias com a História das Mentalidades ou com a Filosofia, defendendo que estes âmbitos não se confundem, mas são portadores de afinidades. $\mathrm{O}$ autor pugna por uma abrangência temática na e da História das Ideias que não repugnaria, julgamos, à História das mentalidades, indo mais além:

O nível de apreensão a que me reporto situa-se desde o domínio do consciente ao domínio do inconsciente (através da elaboração analítica deste, por certo), insere-se no estudo das instituições, das mentalidades, do utópico, do sacral, do banal, de uma temática abarcadora do "coup de poing" ao computador, de Zeus ao Grande Gatsby, da troca direta à opção zero (...) (PEREIRA, 1992a: 20).

Este historiador das idéias salvaguarda a importância das tensões políticas, culturais e religiosas numa perspetiva explicativa e, em nosso entender, interpretativa "que categorize convenientemente o dramático e o problemático da temporalidade" (PEREIRA, 1992a: 21). Esteves Pereira pugna por uma história das ideias problematizante (interrogante, nos seus próprios termos) e global, na senda de Silva Dias: "Reportando-nos ao "topos basilar" do interrogante, dimensão primacial (...) A História das ideias é uma ciência compreensiva, de sentido globalista, de mediação significativa e de raiz indutiva (...) não é uma história setorial (...)" (PEREIRA, 1992a: 24).

Por seu turno, o artigo Sobre a História das Ideias. II, dado à estampa pela primeira vez a 22 de Maio de 1984, amplia algumas temáticas expostas anteriormente e acrescenta outras. Começa por reforçar a necessidade que alguns filósofos sentiram de se dedicarem a questões metodológicas e epistemológicas do foro da história, dado que os historiadores refletiam de forma escassa sobre essa vertente do seu trabalho. Concordamos parcialmente com esta idéia, dado que os cultores de Clio sempre manifestaram, pelo menos desde o século XIX, preocupações metodológicas, debruçando-sesobre elas, faltando-lhes um aprofundamento mais teorético. Mas há exceções que confirmama regra. 
Esteves Pereira analisa a obra dirigida por Preston King, publicada em 1983 sobre The History of Ideas. An Introduction toMethod, considerando equivocas as leituras que nela veem apenas ou principalmente a defesa de uma história especializada, ainda que dela possa partir para abordar o discurso histórico numa perspetiva mais geral, partilhada pelo historiador português que limita as influências de Lovejoy sobre o trabalho dirigido por Preston King a um ponto que assinala devidamente, percebendo e apoiando a sua extrapolação: “A construção de um discurso histórico em geral tendo como corolário o seguinte: que a história das ideias, mesmo que a considerássemos pelo viés da especialidade, que pode ter, não deixaria, até nesse nível, de ser um topos privilegiado sobre a reflexão do próprio histórico (...)" (PEREIRA, 1992b: 28). Esteves Pereira considera que a História das Ideias deve abarcar toda a realidade, não sendo apenas relevante a sua componente ideal ou a material, se consideradas isoladamente, resultando fundamental uma integração de ambas. Torna-se interessante verificar que Esteves Pereira sente necessidade de citar uma experiência portuguesa, a do Instituto de História e Teoria das Idéias, fundado em 1974 em Coimbra num contexto em que, no departamento de História (genericamente falando), dominava uma alegado viés económico-social, que foi sendo reenquadrado de forma a conjugar a pesquisa sobre as ideias com o estudo acerca das sociedades: "Parece-me de reiterar a importância das experiências portuguesas. Começo pela que nasceu e vive no Instituto de História e Teoria das Ideias da Universidade de Coimbra. (...). Foi notório o confronto havido entre uma prática económico-social e os correlatos de várias histórias das ideias (...)" (PEREIRA, 1992b: 29-30).

Quando escreveu estas palavras, Esteves Pereira já se encontrava a lecionar desde Janeiro de 1981, há três anos, na Faculdade de Ciências Sociais e Humanas da Universidade de Lisboa, em busca de uma concretização da interdisciplinaridade. Em nosso entender, o auto não se exime, de modo sutil e discreto a apontar o viés social da experiência coimbrã, ainda que lhe note evoluções que considera positivas, procurando um exercício de aproximação entre as duas estruturas.

No que tange à relação entre a história das idéias e a filosofia, Esteves Pereira volta a esta questão, aflorada anteriormente, reafirmando que se trata de âmbitos diversos, mas que se podem relacionar, desde que se ultrapasse uma filosofia tradicional, assente em filosofemas tratados como se fossem desprovidos de historicidade, resultando atópicos, acrónicos e perenes. Parece implícita a crítica a uma certa forma de ver o pensamento de Lovejoy, por muitos tido como defensor de uma essência formal das 
ideias, desligada da realidade e do de devir. Essa realidade e esse devir são defendidos por Esteves Pereira, na linha do que fizera Silva Dias, mas de modo pessoal: fazendo apelo à metodologia de Rorty, que indaga meta-reflexivamente a crise e os limites da filosofia, colocando em causa que esta seja o espelho da realidade, comparecendo, alternativamente, como respetiva construção. Esteves Pereira faz o mesmo relativamente à história das ideias "Muita da pedagogia da história da filosofia, da minha geração, raramente se afastava, de facto, de uma estratégia que envolvia o tratamento de problemas "perenes, eternos", sempre predispostos a posicionamentos alternativos, a-históricos (...)" A finalizar este seu segundo artigo sobre História das Ideias, José Esteves Pereira faz apelo a uma visão holística, dependente da “(...) capacidade do historiador enquanto interrogante, com uma predisposição histórica na sua totalidade, entendendo todo o tempo-para o poder significar" (PEREIRA, 1992b: 46).

Em 2004, Esteves Pereira dedica um capítulo à História das Idéias na obra Percursos da História das Ideias. Nele retoma os temas tratados em 1983, permeáveis agora a uma toada mais emotiva: "Começa por ser difícil escrever sobre o nosso percurso teórico de história das ideias. Confessamos alguma emotividade e menor distanciamento do que aquele que eventualmente possamos ter sobre as matérias que ao longo do livro o leitor pode avaliar. (...) seria praticamente impossível não contar com assomos de memória vivenciada (...)" (PEREIRA, 2004: 15). No primeiro ponto, o historiador das idéias assume a e existência de uma escola criada e desenvolvida por Silva Dias, sublinhando a sua pertença a ela (a posição de Reis Torgal é, neste aspeto, coincidente).

Em jeito de resumo dos dois textos de 1983, uma matéria que surge na coletânea de 2004 aparece como relativa novidade e prende-se com a questão do presentismo, patente no segundo ponto do capítulo Sobre a História das Ideias. Em nosso entender, Esteves Pereira absorve a perspetiva de Silva Dias, assimilando-a, mas acrescenta-lhe uma visão a nosso ver tributária de Rorty, não citado explicitamente neste andamento, uma vez que o Passado e o Presente não são essenciais, existem historicamente, como considerara o mestre (PEREIRA, 2004. 19-20).

Todavia, Esteves Pereira aprofunda a presencialidade, segundo a qual só se pode conhecer o passado através do presente, sendo aquele cognoscível apenas como representação da realidade, de modo indireto, mediatizado, instaurador de dúvida permanente: 
cumpre afirmar que, no que ao território do historiador das idéias respeita, nos enfrentamos com o que podemos saber do passado, e pode pôr-se em juízo que todo o conhecimento é exclusivamente presente. Mas há dois aspetos que nos reenviam para a presencialidade como antinomia. Primeiro: se as ideias que, por hipótese, atribuímos a um passado são agora pensadas no presente, então a hipótese carece de bases, pois é demonstrável evidência serem pensadas no presente: mas, noutra instância, se as ideias que sabemos serem pensadas no presente são atribuídas ao passado, não podemos saber sequer se a atribuição é válida, pois não podemos realmente pensar estas ideias presentes no passado (PEREIRA, 2004: 19-20).

Acresce que, no terceiro ponto da argumentação em consideração, Esteves Pereira alarga e extrapola o ponto de vista do mestre e considera não que o passado não é só acessível através deconstruções, (dando importância às ações dos agentes históricos sem se eximir à relevância das ações refletidas) reconhecendo também a performatividade do trabalho historiográfico, na linha dos pratical pasts de Oakshott, afastando-se, todavia, das ressonâncias hegelianas que estes possam ter e valorizando a consignação do facto, da imagem, do mito e do imaginário, sem confundir, contudo, o trabalho historiográfico com ficção:

Claro que pensamos que se deve ter sempre enta que a tradução imagética da fenomenalidade do histórico não se pode confundir com ficção histórica: por muito sugestivas que sejam certas recriações, e entre nós até têm sido exageradamente exaltadas, uma coisa é a sugestão, outra o tratamento histórico da informação, em que a própria localização periodizadora, não sendo uma obsessão, não deve implicar escamoteamento ou ausência. (PEREIRA, 2004, 22).

Na Coletânea de 1992, as referências a Lovejoy são mais episódicas e menos desenvolvidas do que na de 2004. Nesta, mais precisamente no quarto ponto do capítulo sobre a história das ideias, Esteves Pereira nota uma progressiva abertura a uma perspetiva pluridisciplinar por parte do autor de The Great Chain of Being, criticando-o, por outro lado, por não encarar, alegadamente, a ideia como algo multifacetado e enquanto realidade historicamente situada, na variedade e totalidade das suas formas: "O que nos pode merecer mais reservas é o topos do tratamento das ideias na historiografia 
de Lovejoy. Pois a história das ideias só nos parece viável enquanto a ideia se assume como realidade (wirklichkeit) e não no mundo de um imponderável Geistgeschichte".

O historiador das ideias português aproveita por se solidarizar com Mandelbaum quando este encontra ressonâncias diltheyanas em The Great Chain of Being e com Leo Strauss por considerar impossível um estudo de filosofia política divorciado da história. No último ponto da sua análise, Esteves Pereiraretoma e repete alguns pontos de vista patentes mormente no segundo artigo de 1983, elucidando certos aspetos e direcionandose para uma defesa da história das ideias filosóficas. Enquanto a história das ideias tout court se ocupava do homem, a da filosofia dirigia-se ao pensamento dos filósofos. A história das ideias filosóficas estuda as ideias no seu contexto histórico, na sua tradição. Aqui Esteves Pereira assume o legado de Miranda Barbosa e o historicismo nele presente, mas também característico do já referido Leo Strauss: "A preocupação de uma ontognoseologia intencionada à aporia do histórico no seio de todo o pensar possível, sem com isso perturbar a matriz analítica e sistemática foi, aliás, fecundamente problematizada com Miranda Barbosa (1916-1973)”.

António Braz Teixeira concorda com este diagnóstico, mas defende que a influência de Silva Dias sobre Esteves Pereira terá sido ainda maior, ponto de vista que corroboramos:

Integrado na segunda geração que em Coimbra recebeu o alto magistério filosófico de A. Miranda Barbosa, cuja figura evoca e cujo pensamento estuda, (...) José Esteves Pereira, se não deixou nunca de reconhecer a importância que tal magistério teve na sua formação intelectual, foi, no entanto, no ensino de José Sebastião da Silva Dias que encontrou a mais direta e duradoura inspiração para o caminho que viria a escolher, o da História das Ideias, fazendo parte do grupo de investigadores que o autor de Portugal e a Cultura europeia formou em Coimbra- ao lado de Luís Manuel Reis torgal, Fernando Catroga, Amândio Coxito, José Eduardo Horta Correia, João Almeida Policarpo e Jaime Raposo da Costa- e tendo depois acompanhado o mestre quando este se transferiu da Universidade de Coimbra para a Universidade Nova de Lisboa, vindo a suceder-lhe na direção do Centro de História da Cultura e na Revista Cultura(...) (TEIXEIRA, 2004: 8-9).

No que concerne à Última Lição de José Esteves Pereira, a abordagem que faremos será breve. Desde logo, porque apenas destacaremos do seu percurso biográfico 
as referências teórico-metodológicas e epistemológicas à História das Ideias. Depois porque, na Última lição, o autor replica e reproduz algumas posições patentes nas coletâneas de 1992 e 2004, no primeiro caso sobre o caráter tensional das ideias, entre outros temas. No segundo, dedica-se a retomar, em termos análogos, os assuntos versadosem 2004, mormente a relação entre passado e presente, entre facto e imagem e entre filosofia e história das ideias em busca da história das ideias filosóficas:

Quanto à sedimentação da epistemologia da História das Ideias, que cumpria não perder de vista, queria referir dois momentos essências. Num primeiro momento, usufruindo do espaço que me foi oferecido pelo Jornal de Letras em 1983 e 1984, a que já aludi, e, num segundo momento, a possibilidade de divulgação, em 1992, de intervenções minhas sobre o assunto numa publicação (intitulada Sobre a história das ideias, recolhidas por João Carlos Brigola (...) Em 2004, na longa introdução ao meu livro Percurso da História das Ideias (...) refundi as considerações que, na década de 80, tinham, porventura, demasiados presentes oscontornos do leitor a quem me dirigia, alguns deles inevitáveis adversários. Agora, era um tempo de reflexão mais distanciada, embora sem esquecer as circunstâncias em que tinha sido produzida a argumentação (PEREIRA, 2015: 57-59).

\section{Fontes}

DIAS, José Sebastião da Silva (1982a). Recensão a Cancioneiro da Biblioteca Nacional. Cultura História e Filosofia. Lisboa, Instituto Nacional de Investigação Científica, vol.1, pp.556-557

(1982b). Recensão a Chatelêt, François, Histoire des Ideologies. Savoir et pouvoir du XVIII siècle. Cultura História e Filosofia. Lisboa, Instituto Nacional de Investigação Científica, vol. 1, pp. 553-554.

(1982c). Recensão a Dagen, Jean, L'Histoire de l'esprit humain dans la pensée française de Fontenele, à Condorcet. Cultura História e Filosofia. Lisboa, Instituto Nacional de Investigação Científica, vol. 1, pp. 551-552.

(1982d). Recensão a Dérozier, Albert, Quintana y el nascimiento del liberalismo. Cultura História e Filosofia. Lisboa, Instituto Nacional de Investigação Científica, vol. 1, pp. 552-553.

(1982e). Recensão a Gusdorf, Georges, Les Siences Humaines et la pensée occidentale. VII- La concience revolutionnaire: les idéologues. Cultura História e Filosofia. Lisboa, Instituto Nacional de Investigação Científica, vol. 1, pp. 550-551. (1982f). Recensão a Lima, Ebion, A Congregação do Oratório no Brasil. Cultura História e Filosofia. Lisboa, Instituto Nacional de Investigação Científica, vol. 1, pp. 539-549. 
(1982g). Recensão a Marques, Armando de Jesus, Portugal e a Universidade de Salamanca. Participação dos escolares portugueses no governo do estudo, 1503 1512. Cultura História e Filosofia. Lisboa, Instituto Nacional de Investigação Científica, vol. 1, pp. 555-556.

(1982h). Recensão a Ruders, Carl Israel, Viagem em Portugal, 1798-1802. Cultura História e Filosofia. Lisboa, Instituto Nacional de Investigação Científica, vol. 1, pp. 555-556.

(1983a). Recensão a Abellan, José Luís, El Erasmismo Espanol. Cultura História e Filosofia. Lisboa, Instituto Nacional de Investigação Científica, vol. 2, pp. 528535.

(1983b). Recensão a Abellan, José Luis, Historia critica del pensamento espanhol. Cultura História e Filosofia. Lisboa, Instituto Nacional de Investigação Científica, vol. 2, pp. 535-546.

(1983c). Recensão a Baptista, António Alçada, Peregrinação Interior. Cultura História e Filosofia. Lisboa, Instituto Nacional de Investigação Científica, vol. 2, pp. 552-553.

(1983d). Recensão a Benne, Eduard, Les Lumières en Hongrie, en Europe Centrale et en Europe Orientale. Cultura História e Filosofia. Lisboa, vol. 2, Instituto Nacional de Investigação Científica, pp. 551-552.

(1983e). Recensão a Keohane Nannerl O., Philosophy and state in France-The Renaissance of the Enlightment. Cultura História e Filosofia. Lisboa, vol. 2, Instituto Nacional de Investigação Científica, pp. 547-548.

(1983f). Recensão a Koselleck, Reinhart, Le regne de la critique. Cultura História e Filosofia. Lisboa, Instituto Nacional de Investigação Científica, vol. 2, pp. 549551.

(1983g). Recensão a Mayer, Arno, La persistance de l’ancien regime. L`Europe de 1848 à la Grande Guerre. Cultura História e Filosofia. Lisboa, vol. 2, pp. 521528. Instituto Nacional de Investigação Científica,

(1983h). Recensão a Gaganini, Gianni, Analise de la fede e critica della ragione nella filosofia de Pierre Boyle. Cultura História e Filosofia. Lisboa, Instituto Nacional de Investigação Científica, vol. 2, pp. 548-5429.

PEREIRA, José Esteves (1989). Depoimento do Professor José Esteves Pereira. Ler História. Lisboa, Teorema, vol. 15, pp. 162-163.

(1992a). Sobre a História das Ideias I. In: PEREIRA, José Esteves. Sobre a História das Ideias. Intervenções. Recensões. Lisboa: Centro de História da Cultura da Universidade Nova, pp.15-24.

(1992b). Sobre a História das Ideias II (1992). In: PEREIRA, José Esteves. Sobre a História das Ideias. Intervenções. Recensões. Lisboa: Centro de História da Cultura da Universidade Nova, pp. 25-46.

(2004). Sobre a História das Ideias. In: Percursos da História das Ideias. Lisboa: Imprensa Nacional Casa da Moeda, pp. 15-26.

(2015). A Última Lição. Porto: Fundação Engenheiro António de Almeida.

\section{Referências Bibliográficas}

ÁGOAS, Frederico (2015). História das ideias, história das ciências humanas e sociologia do conhecimento. História, Ciências, Saúde, Manguinhos. Rio de Janeiro, vol. 24, n. 2, pp. 465-482. 
AZENHA, Maria do Rosário (1986). Bibliografia de Silva Dias. Revista de História das Ideias, Coimbra, Instituto de História e Teoria das Ideias, vol. 8, pp. 13-23.

BLANKE, Horst Walter (2005). Towards a New Theory-Based History of Historiography. In: KOSLOWSKI, Peter (ed). The Discovery of Historicity in German Idealism and Historism. Berlim: Springer-Verlag, 2005, pp. 223-267.

GRAFTON, Anthony (2006). The History of Ideas: Percept and Practice, 1950-2000, and beyond. Journal of the History of Ideas. University of Pennsylvania, vol. 67, n. 1, pp. 1-32.

JACOBY, Russel (1992). A New Intellectual History? The American Historical Review, vol. 97, n. 2, pp. 405-434.

KELLEY, Donald (1987). Horizons of Intellectual History: Retrospect, circumspect, Prospect. Journal of History of Ideas, vol. 48, n.1, pp. 143-169

KNIGHT, Carl (2012), Unit-Ideas Unleashed: A Reinterpretation and Reassessment of Lovejovian Methodology in the History of Ideas. Journal of the Philosophy of History. vol.6, pp. 195-217.

MENDES, José Maria Amado (1996). A Renovação da Historiografia Portuguesa. A viragem Universitária. In: TORGAL, Luís Reis; CATROGA Fernando; MENDES, José Maria Amado. História da História em Portugal (Séculos XIX e XX). LISBOA: Círculo de Leitores.

MESQUITA, Gustavo Rodrigues (2011). Da história das ideias à história social das ideias: entre a renovação epistemológica e a prática historiográfica. Em Tempo de Histórias. Brasília, n. 18. pp.7-8.

MOYN, Samuel, SARTORI, Andrew (Eds.) (2013). Global Intellectual History. New York, Clolumbia University Press.

MOYN, Samuel, MAC MAHON, Darrin (Eds.), (2014). Rethinking Modern European Intellectual History. Oxford: Oxford University Press, 2014.

OHARA, João Rodolfo Munhoz (2017). Virtudes Epistêmicas na Historiografia Brasileira (1980-1990). Tese (Doutorado em História). Universidade Estadual Paulista "Júlio Mesquita Filho", Assis, SP.

TEIXEIRA, António Braz (2004). Prefácio. In: PEREIRA, José Esteves, Percursos de História das Ideias. Lisboa: Imprensa Nacional Casa da Moeda, pp. 7-12

TOEWS, John (1987). Intellectual History after the Linguistic Turn: The Autonomy of meaning and the irreducibility of experience. The American Historical Review, vol. 92, n. 4, pp. 879-907.

TORGAL, Luís Reis (2016). Acerca de Silva Dias no seu centenário: evocação em jeito de história e da memória. Revista de História das Ideias. Coimbra, vol. 34, pp. 5785.

WHATMORE, Richard \& YOUNG, Bryan (Eds.) (2015). A Companion to Intellectual History. New Jersey: Wiley-Blackwell.

Artigo recebido em 30 de agosto de 2017.

Aprovado em 7 de novembro de 2017. 